\title{
Differential activity in Heschl's gyrus between deaf and hearing individuals is due to auditory deprivation rather than language modality
}

Velia Cardin, Rebecca C. Smittenaar, Eleni Orfanidou, Jerker Rönnberg, Cheryl M. Capek, Mary Rudner and Bencie Woll

\section{Linköping University Post Print}

\section{Tweet}

N.B.: When citing this work, cite the original article.

Original Publication:

Velia Cardin, Rebecca C. Smittenaar, Eleni Orfanidou, Jerker Rönnberg, Cheryl M. Capek, Mary Rudner and Bencie Woll, Differential activity in Heschl's gyrus between deaf and hearing individuals is due to auditory deprivation rather than language modality, 2016, NeuroImage, (124), 96-106.

http://dx.doi.org/10.1016/j.neuroimage.2015.08.073

Copyright: 2015 The Authors. Published by Elsevier B.V. This is an open access article under the CC BY-NC-ND license.

$\underline{\text { http://www.elsevier.com/ }}$

Postprint available at: Linköping University Electronic Press

http://urn.kb.se/resolve?urn=urn:nbn:se:liu:diva-123221 


\title{
Differential activity in Heschl's gyrus between deaf and hearing individuals is due to auditory deprivation rather than language modality
}

\author{
Velia Cardin a,b,*, Rebecca C. Smittenaar ${ }^{\mathrm{c}}$, Eleni Orfanidou ${ }^{\mathrm{a}, \mathrm{d}}$, Jerker Rönnberg ${ }^{\mathrm{b}}$, Cheryl M. Capek ${ }^{\mathrm{e}}$, \\ Mary Rudner ${ }^{\mathrm{b}, 1}$, Bencie Woll ${ }^{\mathrm{a}, 1}$ \\ a Deafness, Cognition and Language Research Centre, 49 Gordon Square, University College London, London WC1H 0BT, UK \\ ${ }^{\mathrm{b}}$ Linnaeus Centre HEAD, Swedish Institute for Disability Research, Department of Behavioural Sciences and Learning, Linköping University, Sweden \\ c Experimental Psychology, 26 Bedford Way, University College London, London WC1H OAP, UK \\ ' School of Psychology, University of Crete, Greece \\ e School of Psychological Sciences, University of Manchester, Manchester M13 9PL, UK
}

\section{A R T I C L E I N F O}

\section{Article history:}

Received 7 April 2015

Accepted 24 August 2015

Available online 5 September 2015

\section{Keywords:}

Heschl's gyrus

Deafness

Sign language

Speech

fMRI

\begin{abstract}
A B S T R A C T
Sensory cortices undergo crossmodal reorganisation as a consequence of sensory deprivation. Congenital deafness in humans represents a particular case with respect to other types of sensory deprivation, because cortical reorganisation is not only a consequence of auditory deprivation, but also of language-driven mechanisms. Visual crossmodal plasticity has been found in secondary auditory cortices of deaf individuals, but it is still unclear if reorganisation also takes place in primary auditory areas, and how this relates to language modality and auditory deprivation.

Here, we dissociated the effects of language modality and auditory deprivation on crossmodal plasticity in Heschl's gyrus as a whole, and in cytoarchitectonic region Te1.0 (likely to contain the core auditory cortex). Using fMRI, we measured the BOLD response to viewing sign language in congenitally or early deaf individuals with and without sign language knowledge, and in hearing controls.

Results show that differences between hearing and deaf individuals are due to a reduction in activation caused by visual stimulation in the hearing group, which is more significant in Te1.0 than in Heschl's gyrus as a whole. Furthermore, differences between deaf and hearing groups are due to auditory deprivation, and there is no evidence that the modality of language used by deaf individuals contributes to crossmodal plasticity in Heschl's gyrus.
\end{abstract}

(c) 2015 Published by Elsevier Inc

\section{Introduction}

Sensory cortices preferentially process inputs from a single modality. However, if input from the preferred modality is absent, these cortices reorganise to process input from other sensory modalities (see Merabet and Pascual-Leone, 2010 for a review). This reorganisation takes place in the cortices of both the absent and intact modalities (Sadato et al., 1998; Bavelier et al., 2001; Finney et al., 2001; Giraud et al., 2001). Evidence suggests that cortical regions preserve their computational function after plastic reorganisation, but adapt to process a different type of sensory input (Lomber et al., 2010; Meredith et al., 2011; Reich et al., 2011; Striem-Amit et al., 2012; Cardin et al., 2013). Congenital or early auditory deprivation in humans has unique features

\footnotetext{
* Corresponding author at: Deafness, Cognition and Language Research Centre, 49 Gordon Square, University College London, London WC1H OPD, UK, and Linnaeus Centre HEAD, Swedish Institute for Disability Research, Department of Behavioural Sciences and Learning, Linköping University, Sweden.

E-mail address: velia.cardin@gmail.com (V. Cardin).

1 These authors contributed equally to this study.
}

with respect to other types of sensory deprivation (i.e., visual) because such individuals not only lack stimulation in a sensory modality, and so will process other modalities preferentially, but they will also have very limited or no access to heard and spoken language, the main form of human communication. Therefore, visual strategies, such as speechreading (lipreading) and sign language, develop in response to the need to communicate. Furthermore, late detection of deafness in children with parents who communicate in spoken language can also result in late language acquisition, with consequent functional and anatomical effects on cortical development and organisation. Thus, the plastic reorganisation observed in the cortex of deaf individuals is the result of the interplay between sensory deprivation- and languagedriven mechanisms.

Studies of language and sensory processing in deaf and hearing populations have contributed to our understanding of the differential contribution of each of these factors to plastic changes in regions associated with auditory processing in hearing individuals, in particular in secondary auditory cortices, such as the superior temporal cortex (STC). In the left STC of deaf individuals, a region associated with speech processing in hearing individuals (e.g. Scott and Johnsrude, 2003), and 
in the anterior-medial part of the right STC, activity has been shown in response to sign-language stimulation (Neville et al., 1998; Rönnberg et al., 1998; MacSweeney et al., 2008; Cardin et al., 2013) and speechreading (Capek et al., 2008), but not in relation to general visual processing (Finney et al., 2001; Cardin et al., 2013). In contrast, the right posterior STC shows responses to general visual stimulation, independently of language experience, pointing towards an effect associated with auditory deprivation (Finney et al., 2001; Fine et al., 2005; Sadato et al., 2005; Cardin et al., 2013). These results suggest that in the case of an interplay of sensory and linguistic factors in plastic reorganisation, each of these factors has an effect on different regions of the cortex.

Even though there is a large body of evidence for plastic reorganisation in secondary auditory areas after auditory deprivation, it is still unclear if visual crossmodal reorganisation also takes place in primary auditory areas, and how this is influenced by language experience and sensory deprivation. In models of auditory processing in nonhuman primates, primary auditory areas are grouped in a "core" region, and secondary areas are grouped in "belt" and "parabelt" regions, located concentrically around the core (see Hackett, 2011 for a review). The core regions represent the first level of cortical auditory processing, and the surrounding belt and parabelt regions support higher levels of processing. Evidence from animal studies suggests a degree of crossmodal plasticity driven by auditory deprivation in core auditory areas. After auditory deprivation, visual crossmodal plasticity has been shown in mice core auditory areas A1 (primary auditory area) and AAF (anterior auditory field; Hunt et al., 2006), and somatosensory crossmodal plasticity also in A1 and AAF in mice and ferrets (Hunt et al., 2006; Meredith and Allman, 2012). In congenitally deaf cats, Kral et al. (2003) did not find visual or somatosensory crossmodal plasticity in A1. However, in AAF, neurons do show responses to visual and, more strongly, somatosensory stimulation (Meredith and Lomber, 2011). In deaf humans it is less obvious if there is plasticity in these regions, in particular because the exact composition of the core auditory cortex and its functional organisation is still a matter of controversy. In humans, the auditory core is located in Heschl's gyrus (HG), an anatomical landmark that is absent in other mammals, including primates. Even though different functional and cytoarchitectonic maps of HG have been described (Morosan et al., 2001; Formisano et al., 2003; Talavage et al., 2004; Woods et al., 2009; Humphries et al., 2010; Da Costa et al., 2011; Striem-Amit et al., 2011; Dick et al., 2012), the exact correspondence between these regions and those in other species is not clear. Several studies agree that there are two tonotopic maps within the core region (potentially corresponding to the homologous macaque A1 and R; Formisano et al., 2003; Talavage et al., 2004; Woods et al., 2009; Da Costa et al., 2011; Striem-Amit et al., 2011; Dick et al., 2012; De Martino et al., 2014; Langers, 2014; Schönwiesner et al., 2014), but their exact orientation with respect to HG is under debate. A different approach is to characterise primary auditory areas based on their microstructural anatomical properties. In a study that quantified the level of myelination across HG in vivo, Dick et al. (2012) found that the highly myelinated auditory core occupies the medial 2/3 of HG. In a post-mortem cytoarchitectonic analysis of HG, Morosan et al. (2001) defined three distinct areas (from postero-medial to antero-lateral): Te1.1, Te1.0, and Te1.2. Based on its granularity (Morosan et al., 2001; Hackett, 2011) and anatomical correspondence to the auditory core identified in Dick et al. (2012)'s myelination analysis, Te1.0 is the area likely to represent the human auditory core in the brain of hearing adults. It is still unknown if this is also the case for deaf individuals.

Anatomical definitions are vital in studies with deaf humans, given that tonotopic mapping is not possible. Morphometric differences in the white matter/grey matter ratio between deaf and hearing individuals in HG (Emmorey et al., 2003; but see Lyness et al., 2014), provide an anatomical correlate for potential visual crossmodal plasticity.

Previous studies suggested some level of functional plasticity in primary auditory areas (e.g. Finney et al., 2001; Fine et al., 2005;
Lambertz et al., 2005), showing activations in auditory cortices that extended to HG, potentially including primary auditory areas. However, all these studies consisted of group analyses, where whole brain activations are averages across participants. Given that HG is a small region and highly variable across individuals (Penhune et al., 2003), smoothing and averaging across subjects in a group analysis can lead to inclusion of activations from neighbouring regions. Thus, it is not possible to assign activations to primary auditory areas without a clear anatomical definition of the regions.

In a recent study of congenitally deaf native signers, in which subregions of HG were delineated anatomically, Karns et al. (2012) showed plastic reorganisation in HG in response to the presentation of separate (unimodal) and combined stimuli (bimodal) consisting of air-puffs (somatosensory stimulation) and light flashes (visual stimulation), stronger and more significantly for the somatosensory modality. A subsequent study showed differences in the level of activation of HG, between deaf and hearing individuals, in response to perifoveal $\left(2-7^{\circ}\right)$ and peripheral $\left(11-15^{\circ}\right)$ visual stimulation (Scott et al., 2014).

Given the detailed anatomical definition, results from these two studies addressed directly the question of cortical plasticity due to auditory deprivation in HG. However, they used basic sensory stimulation, without linguistic content, and they were all performed in deaf native signers. It is therefore possible that responses observed were driven by top-down effects from language processing areas which have become responsive to a visuo-spatial language. In hearing individuals, activity in Te1.0 is modulated by the perceived clarity of speech, independently of differences in basic acoustic properties of the stimuli (Wild et al., 2012). Effects in HG are also observed with visual language signals. Speech can also be perceived visually as movements of the face and mouth (speechreading), and both auditory and visual signals contribute to our final perceptual experience (McGurk and MacDonald, 1976; Campbell, 2008). Speechreading (lipreading) not only activates regions typically considered secondary auditory areas or speech processing centres, in both deaf and hearing individuals (Söderfeldt et al., 1997; see Campbell, 2008 for a review), but it also activates regions of HG, more towards its lateral portion (Calvert et al., 1997; Calvert et al., 2000; Pekkola et al., 2005). This activation is significantly greater in the left temporal cortex, including the planum temporale and HG (Capek et al., 2008), in congenitally deaf participants (native signers who are also proficient speechreaders) than in hearing nonsigning controls. Furthermore, enhanced responses are observed in the left HG when auditory and visual speech signals are combined (Calvert et al., 2000).

In addition to the evidence presented above, which suggests that language use (speech and sign) in deaf individuals might result in different crossmodal plasticity in primary auditory areas, the fact that the grey and white matter volume in several brain structures changes according to language experience in deaf individuals, suggests that results from deaf native signers cannot be generalised (Olulade et al., 2014). Characterising which of the components of plastic reorganisation in primary auditory areas of deaf individuals are caused by language modality and which by auditory deprivation is not only important for understanding the basic mechanisms of plastic reorganisation, but also because of its relevance in terms of approaches to language acquisition in deaf children, in particular those who have cochlear implants (CI) or are waiting to receive one. Even though several pieces of evidence show that crossmodal plasticity correlates with CI success (Giraud et al., 2001; Rouger et al., 2007; Mangus et al., 2012; Stevenson et al., 2012), and that speech acquisition in hearing individuals involves the integration of auditory and visual inputs (Mills, 1987; Lewkowicz and Hansen-Tift, 2012), some studies suggest that plastic reorganisation due to visual language can interfere with $\mathrm{CI}$ success, and that sign language and speechreading could make this interference worse (Teoh et al., 2004; Giraud and Lee, 2007). Here we dissociate the effects of language modality and auditory deprivation on visual crossmodal plasticity in HG, using a subject-specific anatomical definition, and also a subject- 
specific cytoarchitectonic definition of area Te1.0. For this purpose, we measured the fMRI BOLD response to viewing sign language in congenitally or early deaf individuals with and without sign language knowledge, and in hearing controls.

\section{Materials and methods}

\section{Participants}

All participants gave written consent to take part in the study, and all procedures followed the standards set by the Declaration of Helsinki, and were approved by the local ethics committee. Two groups of congenitally or early (before 3 years of age) severely-to-profoundly deaf individuals took part in the study: 1 ) Deaf Signers $(\mathrm{n}=7)$ : who have deaf parents, are native signers of British Sign Language (BSL), and knew spoken and written English; and 2) Deaf Oral ( $\mathrm{n}=7)$ : who have hearing parents, are native speakers of English who access language through speechreading, and who have never learned a sign language. All participants in the group of deaf signers were congenitally deaf due to a genetic aetiology. Five participants in the group of deaf oral individuals were congenitally deaf (aetiologies: 1 genetic, 2 rubella, 2 unknown), and two became deaf before 3 years of age ( 1 meningitis, 1 unknown). All aetiologies and onset of deafness were self-reported. Seven participants with normal hearing who were native speakers of English (Hearing Non-signers) served as a separate control group. All structural scans were visually inspected for anatomical abnormalities.

Groups were matched for: i) sensory loss [only for deaf oral and deaf signers; better-ear Pure Tone Average (PTA; 1 KHz, 2 KHz, 4 KHz; maximum output of equipment $=100 \mathrm{~dB})$ : deaf signers $=98.1 \mathrm{~dB} \pm 3.7$ SEM (range: $81.7->100 \mathrm{~dB}$ ); deaf oral $=94.5 \mathrm{~dB} \pm 3.3$ (range: $81.7->100 \mathrm{~dB}) ; \mathrm{t}(6)=0.64, \mathrm{p}=.54$ ]; ii) age [deaf signers $=$ 46.3 years $\pm 4.4 \mathrm{SEM}$; deaf oral $=47.3 \pm 1$; hearing non-signers $=$ $47.6 \pm 3.3 ; \mathrm{t}(6)$ deaf oral,deaf signers $=0.23, \mathrm{p}=.82 ; \mathrm{t}(6)^{\text {deaf oral, hearing }}=$ $0.09, \mathrm{p}=.93 ; \mathrm{t}(6)^{\text {hearingdeaf signers }}=0.2, \mathrm{p}=.81$ ]; and iii) gender [ 3 male and 4 female in each group]. Participants in the deaf signers and hearing non-signers groups were recruited from local databases. Most of the participants in the deaf oral group were recruited through an association of former students of a local oral-education school. Because of changing attitudes towards SL, deaf people are now more likely to be interested in learning to sign as young adults, even if they were raised in a completely oral environment and developed a spoken language successfully. SL knowledge was an exclusion criterion for the deaf oral group. For this reason, all the participants in the deaf oral group were more than 40 years of age, and participants in the other two groups were selected to match them.

\section{Stimuli}

Results presented in this paper are part of a larger study investigating cross-linguistic differences and phonology in sign language processing, and crossmodal plasticity in signers and non-signers. Whole-brain comparisons across groups have been reported in an earlier paper (Cardin et al., 2013), and further results will be reported elsewhere. Stimuli consisted of videos of sign-based material, each of 2-3 s duration. Stimuli varied systematically in the amount of linguistic information they contained, including: 1) signs of a familiar sign language (British Sign Language, BSL), which deliver semantic and phonological information (to the deaf signer group); 2) signs of an unfamiliar sign language (Swedish Sign Language, SSL), which were possible BSL signs, but which were not part of the lexicon, delivering mainly phonological information; 3 ) cognates, which are lexical signs identical in form and meaning in both BSL and SSL, and likely to build on the general principles underpinning the link between form and meaning in sign language; and 4) invented Non-Signs, which are invented signs that violate the phonological rules of both BSL and SSL. Non-signs were either reported by or created following the procedures described in
Orfanidou et al. (2009). If a differential recruitment of HG in deaf signers exists, this design allows us to determine if the effect is due to linguistic processing elicited by each type of stimuli, or by different linguistic demands of the tasks. There were four scanning runs, each consisting of 12 blocks of 8 videos of the same stimulus type and task, with blank-screen inter-trial interval (ITI) of $4.5 \mathrm{~s}$ on average. Participants were asked to perform either a handshape or a location monitoring task (see below), and prior to each block, a cue picture showed which handshape or location to monitor. A baseline period of $15 \mathrm{~s}$, consisting of an image of the model sitting without making any movement with his hands, appeared in between blocks. Throughout the manuscript, the term 'baseline' will refer to this period while the model was in a static position. This baseline condition is different from blank periods of no visual stimulation, which were also present in between blocks and videos, as described, and that were not explicitly modelled. The participants' task was to indicate with a button-press if the sign presented in each video had the same hand-shape or same location as a cue presented just before the onset of the block. This is a phoneme monitoring task (cf. Grosvald et al., 2012) for signers, but can be performed as a purely perceptual matching task by non-signers. Performance in the task was evaluated by calculating reaction times and $\mathrm{d}^{\prime}$. The latter was calculated by counting each detected button press as a positive answer (either hits or false positives), and equating instances in which participants did not press the button as 'no' answers (either correct rejections or misses).

\section{Data acquisition}

Functional gradient-echo EPI images (TR $=2975 \mathrm{~ms}, \mathrm{TE}=50 \mathrm{~ms}$, FOV $=192 \times 192 \mathrm{~mm}$, voxel size $=3 \mathrm{~mm}^{3}$, 35 slices) were acquired on a Siemens Avanto $1.5 \mathrm{~T}$ scanner equipped with a 32-channel head coil at the Birkbeck-UCL Centre for Neuroimaging. The first 7 volumes of each run were discarded to allow for T1 equilibration effects. A structural image was collected for each participant using MP-RAGE $\left(\mathrm{TR}=2730 \mathrm{~ms}, \mathrm{TE}=3.57 \mathrm{~ms}\right.$, voxel size $=1 \mathrm{~mm}^{3}, 176$ slices $)$.

\section{Data analysis}

Functional data were analysed using Matlab 7.10 (MathWorks Inc., MA, USA) and SPM8 (Wellcome Department of Cognitive Neurology, London, UK). For each participant separately, all EPIs were realigned and then coregistered to each individual's anatomical scan. These EPIs were used for extracting percent signal changes from the Heschl's gyrus ROI (HG ROI; see below). EPIs were then normalised for use with the standard definition of cytoarchitectonic region Te1.0. The anatomical image was normalised to SPM's standard MNI template image, and the parameters from this normalisation were used to normalise all the EPIs. No spatial smoothing was applied.

Each individual's Heschl's gyri were defined using FreeSurfer 5.0.0 (http://surfer.nmr.mgh.harvard.edu/). Complete descriptions of these procedures are provided in previous publications (Dale et al., 1999; Fischl and Dale, 2000; Fischl et al., 2001, 2002, 2004; Ségonne et al., 2004; Han et al., 2006; Jovicich et al., 2006). In short, brightness and contrast normalisation were performed on the images, followed by removal of all non-brain tissues with a hybrid watershed/surface deformation procedure (Ségonne et al., 2004). Talairach transformations were then applied to the images, and subcortical white matter and deep grey matter structures were segmented (Fischl et al., 2004). The grey white matter boundary was then tessellated with automatic correction of topology (Fischl et al., 2001; Ségonne et al., 2004). Surface deformation was then performed using intensity gradients, optimally placing the grey/white and grey/CSF borders where the greatest change in intensity indicates transition to the other tissue classes (Dale et al., 1999).

Following completion of the cortical reconstruction, the surface was inflated (Dale et al., 1999), and registered to a spherical atlas (individual 
cortical folding patterns used to align cortical geometry across subjects). Anatomic parcellation was carried out based on gyral and sulcal patterns, a priori anatomical information, and knowledge of neighbouring labels (Fischl et al., 2004). From the Destrieux atlas, voxels within the Heschl's gyrus label (HG ROI) were then exported for use in the ROI analysis. HG ROIs were visually checked to ensure correct delineation of the gyrus.

Area Te1.0 of Heschl's gyrus was defined using the cytoarchitectonic maps generated by Tahmasebi et al. (2009), based on those produced by Morosan et al. (2001). Briefly, Tahmasebi et al. (2009) warped the 10 post-mortem brains and corresponding cytoarchitectonic information of Morosan et al. (2001) into SPM's standard MNI template. This procedure resulted in cytoarchitectonic definitions in a standard space with higher specificity and less overlap with surrounding regions. Subjectspecific cytoarchitectonic ROIs were defined by combining, separately for each participant and each hemisphere, the HG ROI and Tahmasebi et al. (2009)'s cytoarchitectonic maps (Fig. 1). Each participant's HG ROI was normalised, using the parameters generated during normalisation of the anatomical scan, and combined with cytoarchitectonic maps in standard space. Only voxels present in both, the FreeSurfer ROI and the specific cytoarchitectonic ROI, were included in the analysis. Table 1 shows the number of voxels in each ROI for each group of participants. There was a significant difference in the number of voxels in the left Te1.0 between hearing non-signers and deaf oral $(\mathrm{t}(12)=$ $2.78, \mathrm{p}=.017$ ). The difference in number of voxels between deaf oral and deaf signers in right HG ROI approached significance $(\mathrm{t}(12)=$ $1.96, \mathrm{p}=.074)$. $\mathrm{t}$-Tests for all other comparisons across groups were not significant at $\mathrm{p}<.05$ (all $\mathrm{p}>0.99$ ).
Heschl's Gyrus
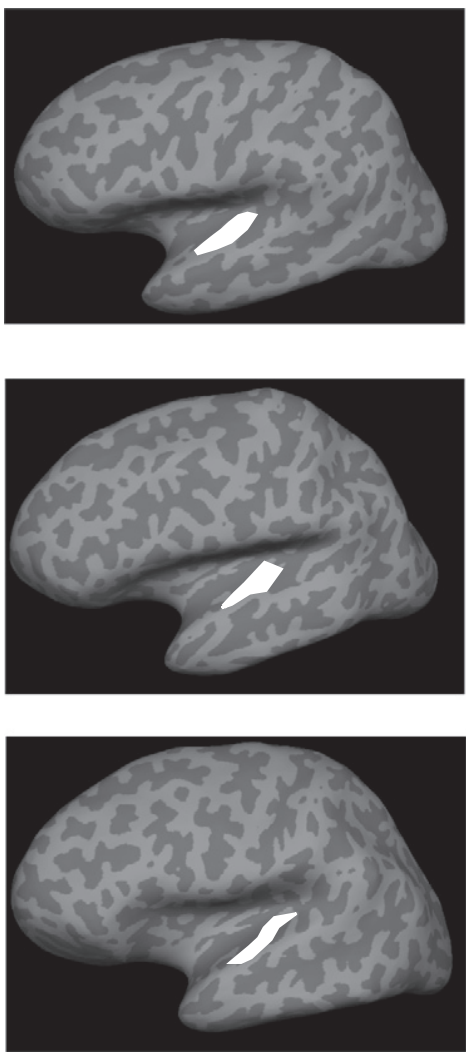

Te 1.0
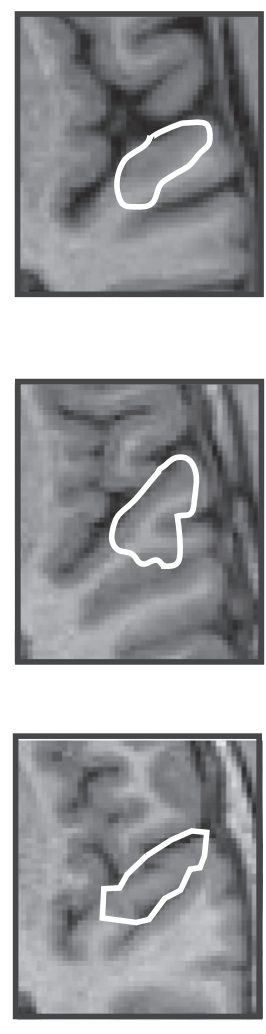

Fig. 1. Participant-specific regions of interest. Left: inflated representations of the brain of three participants, one for each group: hearing non-signers (top), deaf signers (middle), and deaf oral (bottom). The automatically-parcellated Heschl's Gyrus Region of Interest (HG ROI) is shown in white. Right: participant-specific region Te1.0 (white) is shown overlaid on an anatomical slice of Heschl's gyrus for the same participants.
Table 1

Average number of voxels per ROI.

\begin{tabular}{|c|c|c|c|c|c|c|c|c|}
\hline & \multicolumn{2}{|c|}{ Left HG ROI } & \multicolumn{2}{|c|}{$\begin{array}{l}\text { Right HG } \\
\text { ROI }\end{array}$} & \multicolumn{2}{|c|}{ Left Te1.0 } & \multicolumn{2}{|c|}{ Left Te1.0 } \\
\hline & NV & SD & NV & SD & NV & SD & NV & SD \\
\hline Hearing non-signers & 183.1 & 22.4 & 150.3 & 19.9 & 89.0 & 15.1 & 68.3 & 8.1 \\
\hline Deaf signers & 177.0 & 23.9 & 142.3 & 31.0 & 76.4 & 14.9 & 62.6 & 17.9 \\
\hline Deaf oral & 191.7 & 38.6 & 171.3 & 24.0 & 70.1 & 9.7 & 70.4 & 18.6 \\
\hline
\end{tabular}

The table shows average number of voxels (NV) and standard deviation (SD) for each ROI and each group of participants.

Analysis was conducted by fitting a general linear model (GLM) with regressors representing each stimulus category, task, baseline and cue periods. For every regressor, events were modelled as a boxcar representing its duration, convolved with SPM's canonical hemodynamic response function, and entered into a multiple regression analysis to generate parameter estimates for each regressor at every voxel. Movement parameters were derived from the realignment of the images and included in the model as regressors of no interest. For each participant and each hemisphere, average percent signal change from each ROI was extracted from the baseline and each of the conditions using MarsBar toolbox (http://marsbar.sourceforge.net/) for SPM.

\section{Results}

The goal of our study is to characterise differences in crossmodal plasticity and function of HG caused by auditory deprivation and language modality. Therefore, our analysis concentrated only on identifying the effects driven by differences between groups or interaction between group and stimulus type or task. Main effects of stimulus type or task will reflect differences in basic properties of the stimuli or task demands, and are not relevant for dissociating the effects of auditory deprivation and language modality.
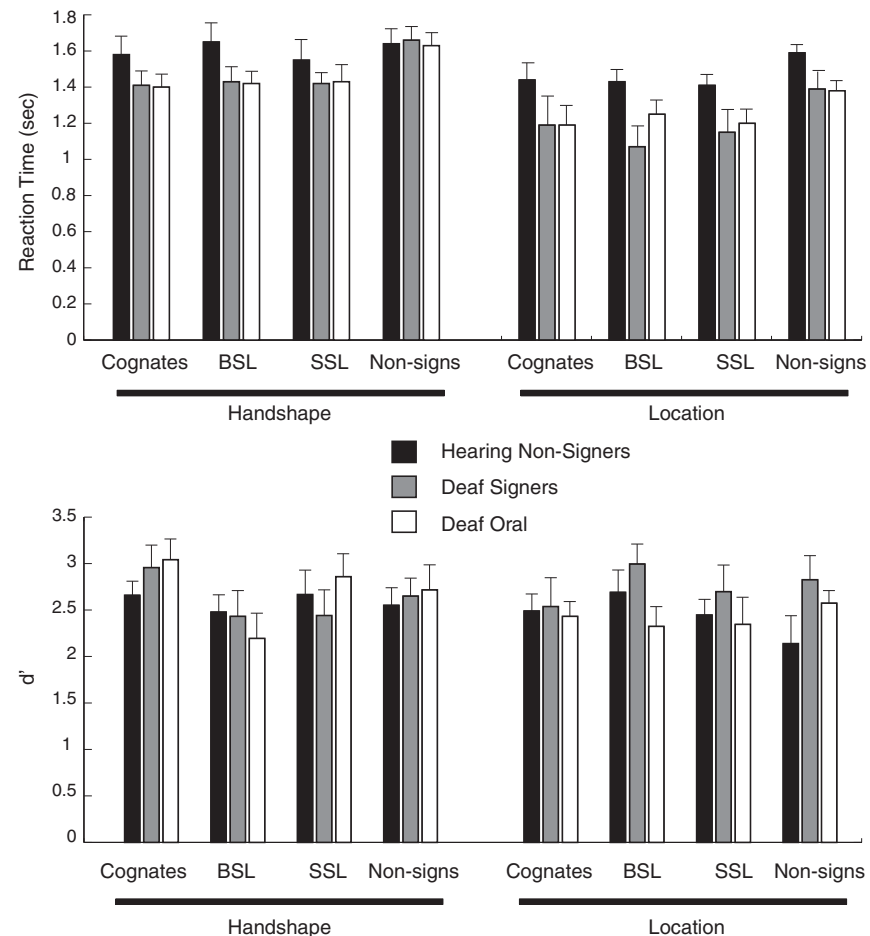

Fig. 2. Behavioural performance. Top: averaged reaction times in seconds for each group. Bottom: averaged d prime values for each group. The bars represent mean \pm S.E.M. BSL: British Sign Language. SSL: Swedish Sign Language. 


\section{Behavioural results}

Performance (accuracy and reaction times) for each task, stimulus type and group of participants is shown in Fig. 2. A repeated measures ANOVA with reaction times as a dependent variable, and factors Group (deaf signers, deaf oral and hearing non-signers), Task (handshape and location), and Stimulus Type (BSL, Cognates, SSL and non-signs) was performed to determine if there were significant differences in performance.

There was a significant main effect of task $(\mathrm{F}(1,18)=47.4, \mathrm{p}<.001)$ and stimulus type $(\mathrm{F}(3,54)=15.5, \mathrm{p}<.001)$, but no significant main effect of Group $(\mathrm{F}(2,18)=2.25, \mathrm{p}=.134)$, and no significant interactions $(\mathrm{F}<1.82$ and $\mathrm{p}>.19$ for all interactions).

Given that we found an effect of group in the neuroimaging data (see below), and there is a trend showing a slower performance in the group of hearing non-signers, we conducted a post-hoc t-test comparing hearing signers to both groups of deaf participants (collapsing across all tasks and stimulus type). This test showed that hearing participants were significantly slower than deaf participants $(t(19)=2.16$, $\mathrm{p}=0.044)$.

A similar repeated measures ANOVA was conducted with accuracy as a dependent variable. There was no significant main effect $(F>1.36$ and $\mathrm{p}>.26$ for all main effects), but there were significant interactions between group $\times$ stimulus type $(\mathrm{F}(6,54)=2.31, \mathrm{p}=.046)$, and task $\times$ stimulus type $(\mathrm{F}(3,54)=3.75, \mathrm{p}=.016)$. There was no significant 3-way interaction $(F(6,54)<1)$. We investigated further the interaction between group $\times$ stimulus type by conducting separate repeated measures ANOVAs on each group, looking for a significant main effect of stimulus type. This significant main effect was only found in the group of hearing non-signers $(\mathrm{F}(3,18)=3.87, \mathrm{p}=.027)$. Post-hoc t-tests reveal that, in this group, performance with non-signs was significantly worse than performance with BSL $(\mathrm{t}(6)=3.00, \mathrm{p}=.024)$ and SSL $(\mathrm{t}(6)=4.62, \mathrm{p}=.004)$, and the difference to cognates approaches significance $(\mathrm{t}(6)=2.11 ; \mathrm{p}=.079)$.

\section{Neuroimaging results}

To determine the contribution of auditory deprivation and language modality to crossmodal visual plasticity in $\mathrm{HG}$, the responses to stimulus types and tasks were analysed in the three experimental groups: i) Deaf Signers; ii) Deaf Oral; and iii) Hearing Non-signers (see Materials and methods). The stimuli and tasks had linguistic content for deaf signers, but only required processing of visuo-spatial information for deaf oral and hearing non-signers. Therefore, any crossmodal effects triggered by auditory deprivation will be observed in both groups of deaf individuals (deaf signers and deaf oral), whereas any due to language modality (i.e. sign language experience) will only be observed in the deaf signers group. First we evaluated if there were differences between the Baseline condition and all the sign conditions (i.e. all tasks and stimulus types) across groups. We analysed responses from all voxels of the anatomical definition of HG ROI, and separately for the subject-specific cytoarchitectonic region Te1.0, which is likely to contain (in hearing individuals) the human homologue of the macaque auditory core. Fig. 3 shows the results from this analysis. The pattern of results is similar with both ROI definitions. However, separate repeated measures ANOVAs for the HG ROI and for Te1.0, with factors Group (deaf signers, deaf oral and hearing nonsigners), Hemisphere (right, left) and Visual Condition (baseline, signs), reveal differences in the significance of the effects (Table 2). Specifically, in Te1.0 there is a main effect of Group and an interaction between Visual Condition $\times$ Group. However, the main effect of Group is not significant when evaluating the response of HG ROI as a whole, and the interaction between Visual Condition $\times$ Group only approaches significance. $t$-Tests from results of Te1.0 reveal a significant difference in the average level of activation between the hearing non-signers group and the deaf signers group $(\mathrm{t}(12)=$ $3.25 ; \mathrm{p}=.007$ ), and the hearing non-signers group and the deaf oral group $(t(12)=2.40 ; p=.034)$, with more positive percent signals changes in both groups of deaf participants. No significant difference was found between the groups of deaf participants $(t(12)=0.28 ; p=.782)$. Comparisons between conditions separately for each group show that the difference between baseline and sign stimulation is only significant in the hearing non-signers group $(\mathrm{t}(6)=3.07 ; \mathrm{p}=.022)$, and not in deaf signers $(\mathrm{t}(6)=0.95$; $\mathrm{p}=.379)$ and deaf oral $(\mathrm{t}(6)=1.05 ; \mathrm{p}=.333)$. These results indicate that the significant interaction between Visual Condition $\times$ Group is due to differences between conditions in the group of hearing individuals, and not in the groups of deaf individuals.

Our sign language stimuli contained different levels of linguistic content, so that if sign language processing occurred in the primary auditory cortex of deaf signers, we would be able to detect the effect. For this purpose we conducted repeated measures ANOVAs with factors Hemisphere (right, left), Group (deaf signers, deaf oral and hearing nonsigners), Task (handshape, location), and Stimulus Type (BSL, Cognates, SSL and Non-Signs) separately for HG ROI and Te1.0. The percent signal change in the baseline condition was subtracted from percent signal changes for each of the sign language conditions. Results show a significant main effect of Group in Te1.0, but not in HG ROI, in agreement with the interaction between Visual Condition $\times$ Group of the previous ANOVA (Table 3). There was no interaction between Stimulus Type $x$ Group, or between Stimulus Type $\times$ Task $\times$ Group, indicating that responses to sign stimuli with different attributes were not different
HG ROI

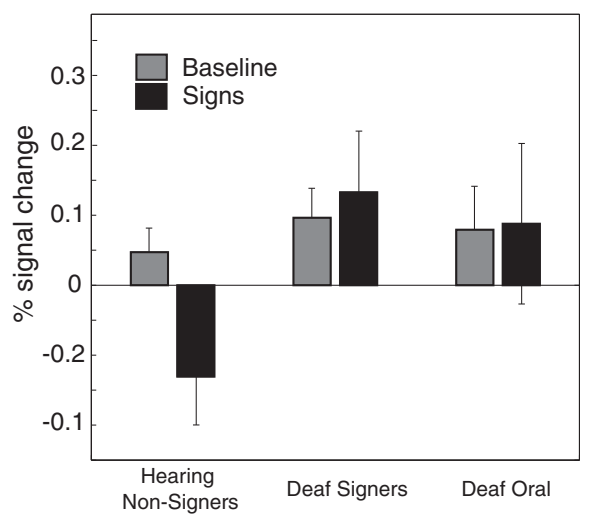

Te 1.0

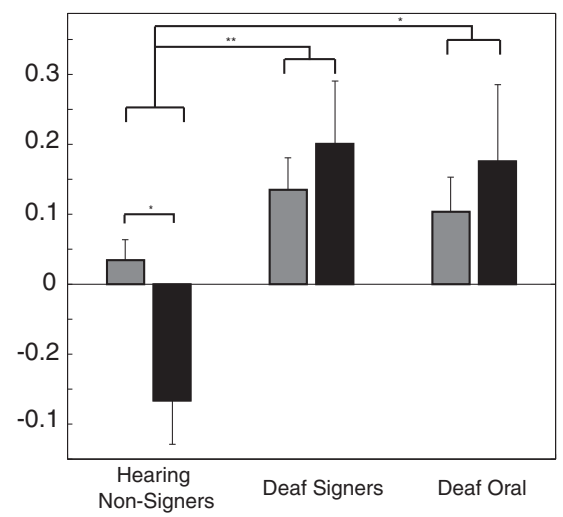

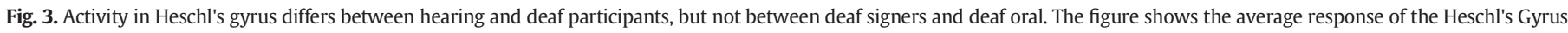

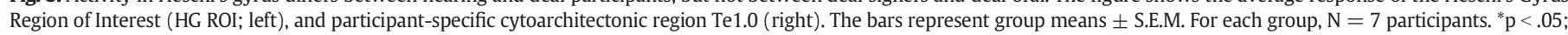
${ }^{* *} \mathrm{p}<.01$. No significant difference between deaf signers and deaf oral in any of the ROIs. 
Table 2

Repeated measures ANOVA with factors Group, Hemisphere, and Visual stimuli.

\begin{tabular}{lccc}
\hline Effect & F & df & p \\
\hline HG ROI & & & \\
Group & 1.63 & 2,18 & .224 \\
Hemisphere & 3.92 & 1,18 & .063 \\
Hemisphere $\times$ Group & $<1$ & 2,18 & .842 \\
Visual stimuli & 1.30 & 1,18 & .270 \\
Visual stimuli $\times$ Group & 2.94 & 2,18 & .079 \\
Hemisphere $\times$ Visual stimuli & $\mathbf{5 . 1 0}$ & $\mathbf{1 , 1 8}$ & $\mathbf{. 0 3 7}$ \\
Hemisphere $\times$ Visual stimuli $\times$ Group & $<1$ & 2,18 & .843 \\
Te 1.0 & & & \\
Group & & & \\
Hemisphere & $\mathbf{4 . 3 0}$ & $\mathbf{2 , 1 8}$ & $\mathbf{. 0 3 0}$ \\
Hemisphere $\times$ Group & $<1$ & 1,18 & .505 \\
Visual stimuli & $<1$ & 2,18 & .555 \\
Visual stimuli $\times$ Group & $<1$ & 1,18 & .597 \\
Hemisphere $\times$ Visual stimuli & $\mathbf{5 . 2 8}$ & $\mathbf{2 , 1 8}$ & $\mathbf{. 0 1 6}$ \\
Hemisphere $\times$ Visual stimuli $\times$ Group & $<1$ & 1,18 & .854 \\
\hline
\end{tabular}

Factors in the analysis were: Group (DS, DO and HN), Hemisphere (Right, Left) and Condition (Baseline, Sign Language Stimuli). Bold letters indicate significant effects.

across groups. Results from HG ROI and Te1.0 are shown in Figs. 4 and 5 (respectively).

\section{Discussion}

Studies of early sensory deprivation in mammals have shown plastic reorganisation of the unstimulated cortices (Hubel and Wiesel, 1970; Lomber et al., 2010; Meredith et al., 2011; Meredith and Lomber, 2011). However, the consequences of early auditory deprivation

Table 3

Repeated measures ANOVA with factors Group, Hemisphere, Task and Stimulus type.

\begin{tabular}{|c|c|c|c|}
\hline Effect & $\mathrm{F}$ & df & $\mathrm{p}$ \\
\hline \multicolumn{4}{|l|}{ HG ROI } \\
\hline Group & 2.94 & 2,18 & .079 \\
\hline Hemisphere & 5.10 & 1,18 & .037 \\
\hline Hemisphere $\times$ Group & $<1$ & 2,18 & .843 \\
\hline Task & $<1$ & 1,18 & .938 \\
\hline Task $\times$ Group & 1.89 & 2,18 & .180 \\
\hline Stimulus type & $<1$ & 3,54 & .778 \\
\hline Stimulus type $\times$ Group & $<1$ & 6,54 & .576 \\
\hline Hemisphere $\times$ Task & $<1$ & 1,18 & .898 \\
\hline Hemisphere $\times$ Task $\times$ Group & $<1$ & 2,18 & .816 \\
\hline Hemisphere $\times$ Stimulus type & 1.72 & 3,54 & .175 \\
\hline Hemisphere $\times$ Stimulus type $\times$ Group & 1.36 & 6,54 & .249 \\
\hline Task $\times$ Stimulus type & $<1$ & 3,54 & .403 \\
\hline Task $\times$ Stimulus type $\times$ Group & 1.39 & 6,54 & .236 \\
\hline Hemisphere $\times$ Task $\times$ Condition & 1.10 & 3,54 & .357 \\
\hline Hemisphere $\times$ Task $\times$ Condition $\times$ Group & $<1$ & 6,54 & .856 \\
\hline \multicolumn{4}{|l|}{$\mathrm{Te} 1.0$} \\
\hline Group & 5.28 & 2,18 & .016 \\
\hline Hemisphere & $<1$ & 1,18 & .854 \\
\hline Hemisphere $\times$ Group & $<1$ & 2,18 & .452 \\
\hline Task & $<1$ & 1,18 & .843 \\
\hline Task $\times$ Group & $<1$ & 2,18 & .529 \\
\hline Stimulus type & 2.27 & 3,54 & .091 \\
\hline Stimulus type $\times$ Group & 1.74 & 6,54 & .128 \\
\hline Hemisphere $\times$ Task & 2.40 & 1,18 & .139 \\
\hline Hemisphere $\times$ Task $\times$ Group & 1.59 & 2,18 & .231 \\
\hline Hemisphere $\times$ Stimulus type & 1.82 & 3,54 & .154 \\
\hline Hemisphere $\times$ Stimulus type $\times$ Group & 1.84 & 6,54 & .109 \\
\hline Task $\times$ Stimulus type & $<1$ & 3,54 & .442 \\
\hline Task $\times$ Stimulus type $\times$ Group & $<1$ & 6,54 & .496 \\
\hline Hemisphere $\times$ Task $\times$ Condition & $<1$ & 3,54 & .429 \\
\hline Hemisphere $\times$ Task $\times$ Condition $\times$ Group & $<1$ & 6,54 & .438 \\
\hline
\end{tabular}

Factors in the analysis were: Group (DS, DO and HN), Hemisphere (Right, Left), Task (Handshape, Location), and Stimulus Type (Cognates, BSL, SSL, Non-Signs). Bold letters indicate significant effects. in humans cannot be easily extrapolated from animal studies. This is because in humans, plastic reorganisation is not only due to auditory deprivation, but also due to the acquisition of language through visual strategies such as speechreading and sign language. It is important to characterise this differential contribution not only to understand plastic reorganisation in the human brain, but also to guide the choice of language and hearing interventions in deaf individuals (Lyness et al., 2013). To our knowledge, our study is the first one dissociating the effects of auditory deprivation and sign language experience on visual crossmodal plasticity in regions of HG which have been defined in a subject-specific manner. Here we show that, in response to visual stimulation with sign language content, differences in activity in HG between hearing and deaf participants are caused mainly by a reduction in activation in the hearing group. In other words, the group of hearing non-signers show reduced activations in all sign conditions compared to the static baseline. Importantly, the lack of significant differences between deaf signers and deaf oral individuals suggests that sign language knowledge does not contribute to the degree of difference between deaf and hearing individuals, nor is there evidence that it causes additional visual crossmodal plasticity in HG.

Differences in activity in Heschl's gyrus between hearing and deaf individuals are due to auditory deprivation, and not sign language use

During the maturation of sensory and cognitive systems, there are periods of maximum plasticity - sensitive periods - in which environmental experience influences the development of the neural components of these systems (Hubel and Wiesel, 1970; Hensch, 2004). In cases of sensory deprivation, either early-induced or congenital, the lack of environmental stimulation in one modality during the sensitive period will prevent the normal development of the system (Kral et al., 2001). On the other hand, the stronger reliance on the remaining sensory modalities also contributes to plastic reorganisation in sensory cortices. In the case of deafness in humans, the picture is even more complex because there is plastic reorganisation not only due to auditory deprivation, but also due to the acquisition of language in a visual modality, either sign language or a reliance on speechreading to process spoken language. In addition, there is a potential delay in language acquisition due to late diagnosis of deafness, or difficulty in obtaining adequate language input in an appropriate modality. This means that the sensitive periods for developing both, auditory function and language, may have passed before access to environmental information is obtained. For cochlear implantation, the success of which is usually measured in terms of speech processing ability, the sensitive period has been found to be during the first 3-4 years of life (Sharma and Campbell, 2011; Kral and Sharma, 2012). However, because of the interplay between a sensitive period for auditory experience, and one for language experience, both of these will contribute and interact towards the sensitive period for CIs (Lyness et al., 2013). Previous studies have compared hearing and deaf native signers in order to dissociate the crossmodal plasticity effects of auditory deprivation from those of sign language knowledge (Neville et al., 1998; MacSweeney et al., 2002; Fine et al., 2005; Sadato et al., 2005; Sakai et al., 2005). However, none of these delineated HG anatomically and in subject-specific manner. Furthermore, deaf and hearing native signers have rather different language use and development (Herman and Roy, 2000; van den Bogaerde and Baker, 2005). Thus, questions remained about the contribution of these two factors to plastic changes in primary auditory regions. In an effort to start understanding the interplay of language and auditory experience in the development of the human brain, our study shows that the difference in activation in Heschl's gyrus between hearing and deaf individuals is the result of auditory deprivation, rather than experience of language in different modalities, either spoken or signed. Specifically, we found that in area Te1.0, which is likely to contain the auditory core in humans, average signal change was also significantly smaller in the group of hearing non-signers compared to each of the groups of deaf 


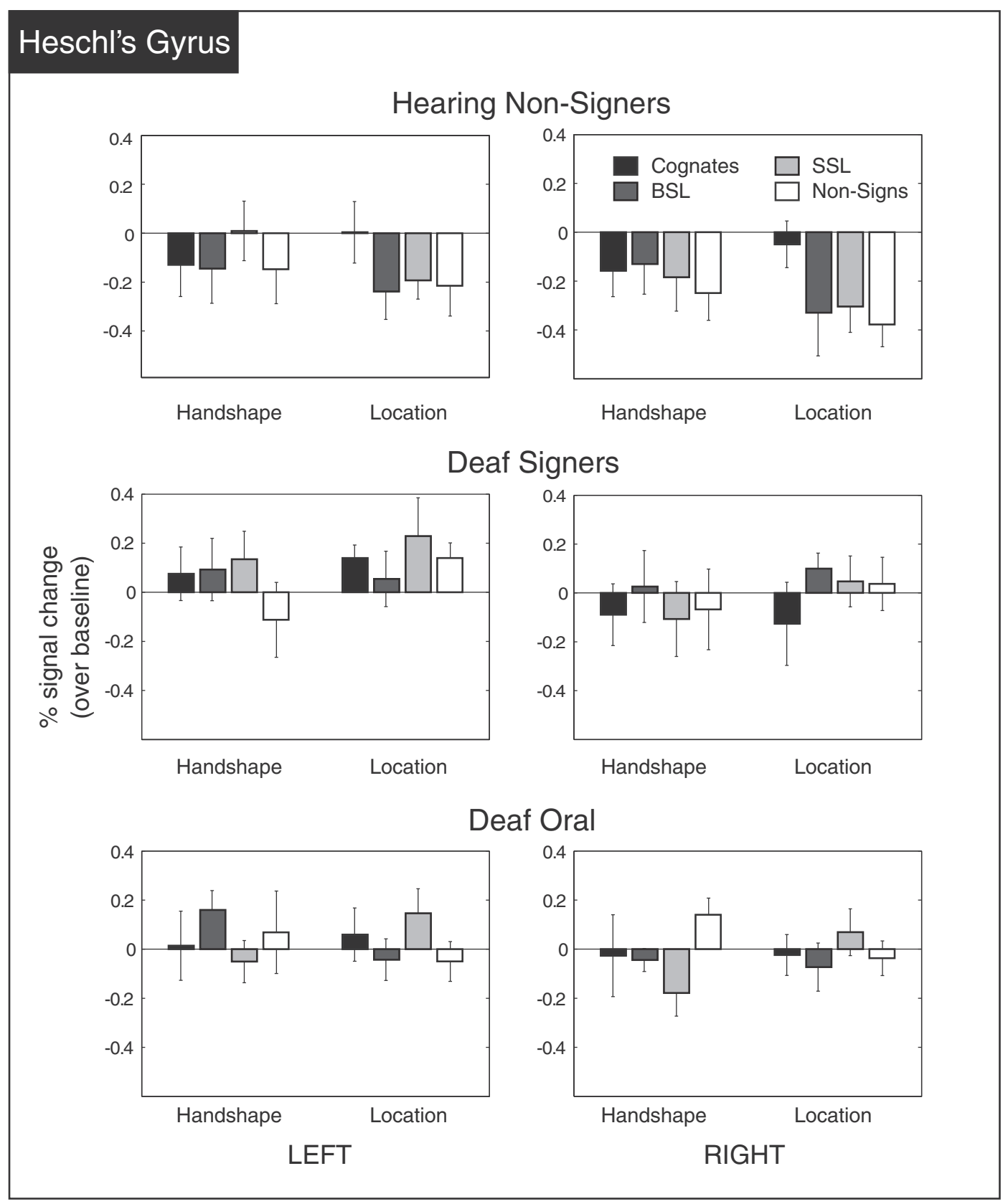

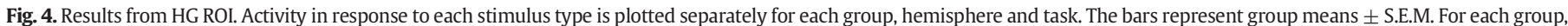
$\mathrm{N}=7$ participants. BSL: British Sign Language. SSL: Swedish Sign Language.

individuals. This was mainly due to a reduction in activation in the hearing group in the signs condition compared to the baseline condition, whereas no significant difference between baseline and signs was found in either group of deaf individuals. On average, no significant difference was found between the group of deaf signers and deaf oral individuals, suggesting that differential use of signed or spoken language does not contribute to further crossmodal plasticity effects in these areas.

We specifically wanted to test the effect of stimuli with linguistic content for deaf signers, in order to rule out the possibility that HG is specifically involved in linguistic processing of signs, rather than general visuo-spatial tasks. A previous MEG study in deaf signers showed that the onset of the activation elicited by single signs in left perisylvian regions falls within a late time window associated with lexicosemantic integration, and not during an early time-window for basic sensory processing (Leonard et al., 2012). This suggests that visual processing of signs in perisylvian areas is associated to linguistic mechanisms, and not to general visual crossmodal plasticity. It also suggests that language regions of the superior temporal cortex are more likely to be the substrates of the MEG effect, rather than primary auditory areas. However, specific distinction between primary auditory cortex and other regions of the temporal cortex cannot be achieved with MEG. Previous studies have also shown a modulation of the activity of areas of HG by visual or spoken language in both hearing and deaf individuals (Calvert et al., 1997, 2000; Pekkola et al., 2005; Wild et al., 2012). Our stimuli contained linguistic content for signers only. Therefore, linguistic processing effects should be observed in deaf signers if at all present. As shown in Figs. 4, 5 and Table 3, there was no significant Group $\times$ Stimulus type interaction in either HG ROI or in Te1.0, suggesting that the primary auditory cortex in humans is not involved in 


\section{Te 1.0}

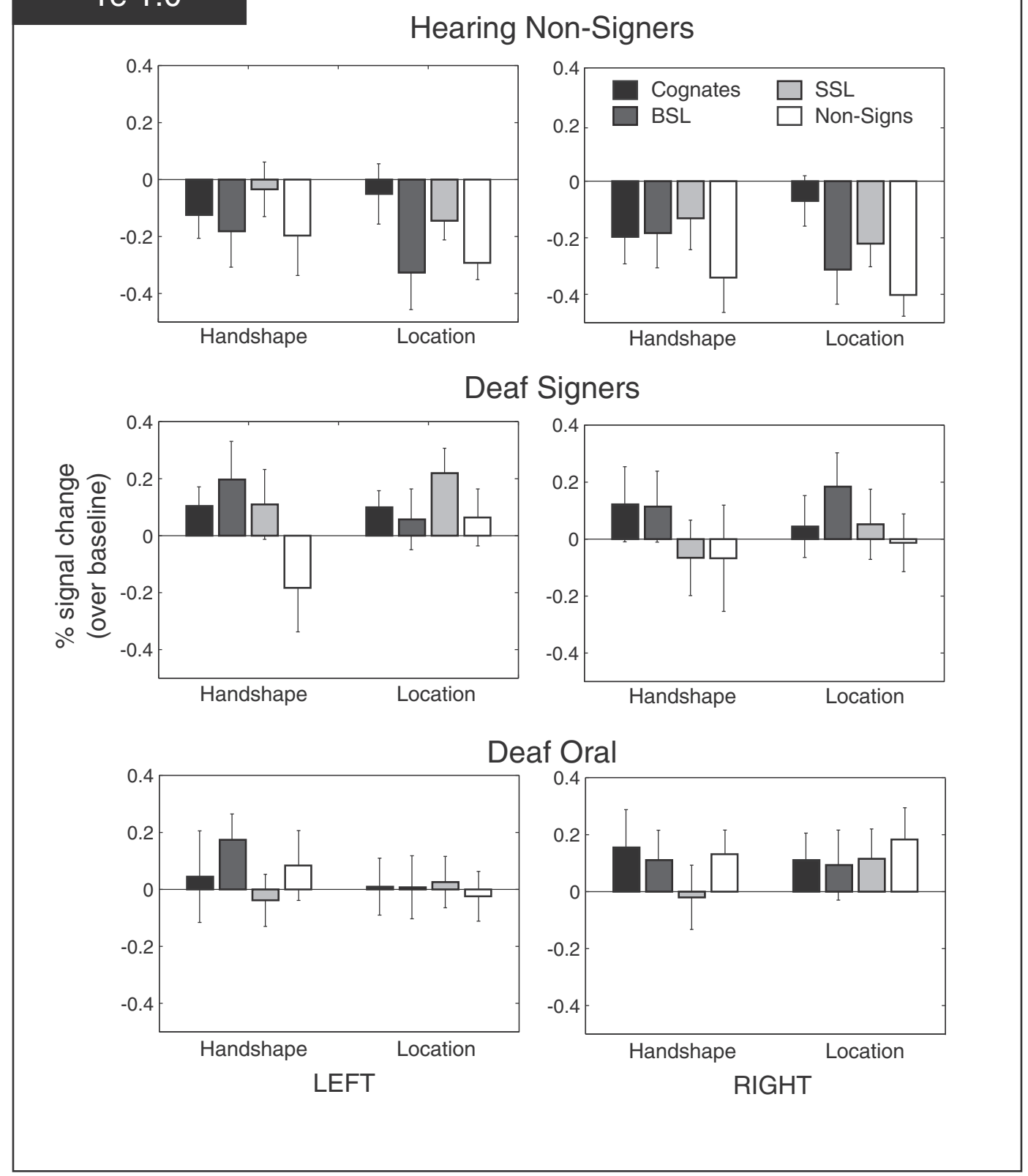

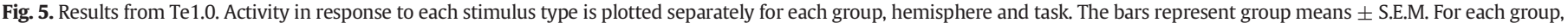
$\mathrm{N}=7$ participants. BSL: British Sign Language. SSL: Swedish Sign Language.

linguistic processing in deaf signers, nor is its activity modulated by linguistic processing in other temporal regions.

\section{Plasticity in areas of the HG}

Differences in the responses between the deaf and the hearing groups were observed more reliably in areas Te1.0 than in Heschl's gyrus as a whole. This highlights the importance of specificity in the definition of primary auditory cortex when comparing deaf and hearing populations, as well as indicating more generally functional differences in subregions of Heschl's gyrus. The human auditory core is located in HG in humans, but its exact location and functional composition in hearing individuals is still a matter of debate (Morosan et al., 2001; Formisano et al., 2003; Talavage et al., 2004; Woods et al., 2009; Humphries et al., 2010; Da
Costa et al., 2011; Striem-Amit et al., 2011; Dick et al., 2012). Furthermore, tonotopic mapping of auditory function in Heschl's gyrus cannot be undertaken in deaf individuals. Given these constraints, anatomical methods, such as a post-mortem cytoarchitecture and myelination analysis (Morosan et al., 2001; Hackett, 2011; Dick et al., 2012), have to be used when trying to characterise responses in the primary auditory cortex of deaf humans. Here we used a post-mortem cytoarchitectonic definition of area Te1.0, a region that is likely to correspond to the auditory core in humans (Morosan et al., 2001). The number of voxels in each ROI was comparable across groups; however, there was a significant difference between hearing non-signers and deaf oral participants in left Te1.0. This suggests potential differences in the morphometry and structure of primary auditory areas as a consequence of auditory deprivation and oral language use. However, our study was not designed to 
address this question, and future studies employing techniques such as quantitative T(1) mapping (Dick et al., 2012) will be necessary in order to answer this.

It is not known if the cytoarchitectonic properties of primary auditory areas are the same in deaf and hearing humans, but evidence from cats shows that the cytoarchitectonic profile of auditory areas in deaf animals, including A1, is the same that found in their hearing counterparts, does not differ from that found in their hearing counterparts, despite significant expansions in secondary auditory cortex and the ventral auditory field (Wong et al., 2014). In any case, the fact that results from Te1.0 are functionally different from those of HG as whole, highlights its relevance in achieving more specific comparisons between deaf and hearing individuals.

Our results also show that differences between deaf and hearing individuals were mainly due to a reduction in activation in the hearing group in response to the signs conditions in comparison to the baseline condition. This reduction in activation was not observed in either of the groups of deaf individuals. This result is in agreement with extensive literature showing reduced or negative activity of unstimulated sensory cortices, or cortices which are unresponsive to the modality of the attended stimuli (e.g. Laurienti et al., 2002; Johnson and Zatorre, 2005). This is also in agreement with results from the study of (Karns et al., 2012), in which the authors compare deaf and hearing participants, and showed reduced (from baseline) activations in HG with visual stimulation (flashing lights) in hearing individuals, but very little difference from baseline in deaf individuals. This reduction in activation is independent of the presence or absence of scanner noise, and it is likely to be caused by top-down mechanisms, such as attention allocation (Johnshon and Zatorre, 2005), one of the goals of which is to reduce noise from sensory modalities which are uninformative for solving a particular task. This effect is absent in the deaf group, which could be due to this top-down inhibitory route not being functional, or simply due to the fact that there is no sensory input (i.e. auditory) that needs to be silenced. A difference between deaf and hearing individuals was also found in reaction times, where hearing individuals were significantly slower. It is possible that this difference in performance is the behavioural reflection of the neuroimaging results in Te1.0, and a consequence of the fact that hearing individuals need to actively suppress auditory activity. However, it should be kept in mind that a reduction in the level of activity of auditory cortices when hearing individuals are performing a visual task is found also in other auditory regions. Thus, we cannot be certain that it is indeed the difference in activity of Te1.0 what is reflected in performance. We also observed a significant interaction between group $\times$ stimulus type in accuracy, which was driven by a poorer performance with Non-Signs in the hearing group. However, this was not reflected either in the results of HG ROI or Te1.0.

If visual crossmodal plasticity in deaf individuals is not significant, at least in Te1.0 and HG as a whole, what role do these cortices have in the deaf brain? Karns et al. (2012) showed somatosensory responses in HG areas in deaf native signers. These responses are stronger than those elicited by visual stimulation. The recruitment of these areas for somatosensation has also been shown in animal studies (Hunt et al., 2006; Meredith and Lomber, 2011; Meredith and Allman, 2012; Wong et al., 2015), and there is a clear anatomical substrate for its development: the cochlear nucleus, the projections of which reach the auditory cortex after several subcortical relays, also receives somatosensory afferents. Evidence demonstrates that after auditory deprivation, neurons in the cochlear nucleus are more responsive to somatosensory stimulation (Shore et al., 2008), and there is also an increase in the number of somatosensory projections reaching the cochlear nucleus (Zeng et al., 2012). Future studies will need to be conducted to determine if the level of somatosensory crossmodal plasticity in core auditory areas is different in signers and non-signers, in particular in those individuals with deaf-blindness, and if this has an effect on cochlear implantation success. However, the evidence of somatosensory crossmodal plasticity after deafness in animals (i.e. independently of language experience), suggests that this is likely to be an effect of sensory deprivation.

Sign language use in deaf children - a confounding effect between language proficiency and language modality

It has been previously shown that responses due to sign language experience in deaf signers are specific for the processing of linguistic information (Leonard et al., 2012; Cardin et al., 2013), and here we show that sign language experience does not produce crossmodal visual plasticity in primary auditory regions. Based on these results, it is unlikely that sign language experience will compromise the cortical processing of auditory signals in $\mathrm{CI}$ users. Nevertheless, some studies have identified language modality as a predictor of CI success, in which children who use communication methods that include exposure to sign language have poorer outcomes than those using exclusively oral communication (e.g. O'Donoghue et al., 2000; Geers, 2002; Wang et al., 2011). An explanation for this apparent paradox is that studies showing an effect of language modality in $\mathrm{CI}$ performance have typically failed to measure sign language proficiency in the children and their parents, or their outcome variables represent more strongly measurements of auditory speech performance, and not general language or sign language knowledge (e.g. O'Donoghue et al., 2000; Geers et al., 2009; Wang et al., 2011). Deaf children with hearing parents often do not receive good sign language input, which means that sign language proficiency in these children can be highly variable. Therefore, any effect of language modality that does not include proficiency measurements may be confounded, and language modality effects could be due to delayed language acquisition related to poor language input. It is also possible that differences exist between deaf signers and non-signers in the processing of visual speech in primary auditory areas. Further studies are needed to elucidate these points.

\section{Conclusion}

In summary, we show that differences between hearing and deaf individuals in primary auditory areas are due to a reduced activations caused by visual stimulation in the hearing group, and that the modality of language used by deaf individuals does not contribute to visual crossmodal plasticity in primary auditory cortex.

\section{Funding}

This work was supported by the Riksbankens Jubileumsfond (P2008-0481:1-E), the Swedish Council for Working Life and Social Research (2008-0846), the Swedish Research Council (349-2007-8654, Linnaeus (entre HEAD), and by grants from the Economic and Social Research Council of Great Britain (RES-620-28-6001; RES-620-28-0002) to the Deafness Cognition and Language Research Centre.

\section{Acknowledgments}

The authors would like to thank Ingrid Johnsrude and Connor Wild for providing the cytoarchitectonic maps and for recommendations for the ROI analysis; Mischa Cooke, Lena Davidsson, Anders Hermansson, Lena Kästner, Ramas Rentelis, Lilli Risner, and Guiping Xu for their help with the recruitment of participants and the acquisition of MRI data; Lena Kästner also for her contribution to the design of the stimuli. We specially thank all the deaf and hearing participants who took part in the study.

\section{References}

Bavelier, D., Brozinsky, C., Tomann, A., Mitchell, T., Neville, H., Liu, G., 2001. Impact of early deafness and early exposure to sign language on the cerebral organization for motion processing. J. Neurosci. 15, 8931-8942. 
Calvert, G.A., Bullmore, E., Brammer, M., Campbell, R., Williams, S., McGuire, P., David, A., 1997. Activation of auditory cortex during silent lipreading. Science 276, 593-596.

Calvert, G.A., Campbell, R., Brammer, M., 2000. Evidence from functional magnetic resonance imaging of crossmodal binding in the human heteromodal cortex. Curr. Biol. 10, 649-657.

Campbell, R., 2008. The processing of audio-visual speech: empirical and neural bases. Philos. Trans. R. Soc. Lond. B Biol. Sci. 363, 1001-1010.

Capek, C.M., Macsweeney, M., Woll, B., Waters, D., McGuire, P.K., David, A.S., Brammer, M.J., Campbell, R., 2008. Cortical circuits for silent speechreading in deaf and hearing people. Neuropsychologia 46, 1233-1241.

Cardin, V., Orfanidou, E., Rönnberg, J., Capek, C.M., Rudner, M., Woll, B., 2013. Dissociating cognitive and sensory neural plasticity in human superior temporal cortex. Nat. Commun. 4, 1473

Da Costa, S., van der Zwaag, W., Marques, J.P., Frackowiak, R.S., Clarke, S., Saenz, M., 2011. Human primary auditory cortex follows the shape of Heschl's gyrus. J. Neurosci. 31, 14067-14075.

Dale, A.M., Fischl, B., Sereno, M.I., 1999. Cortical surface-based analysis: I. Segmentation and surface reconstruction. NeuroImage 9, 179-194.

De Martino, F., Moerel, M., Xu, J., van de Moortele, P.-F., Ugurbil, K., Goebel, R., Yacoub, E., Formisano, E., 2014. High-resolution mapping of myeloarchitecture in vivo: localization of auditory areas in the human brain. Cereb. Cortex pii: bhu150. [Epub ahead of print] PubMed PMID: 24994817.

Dick, F., Tierney, A.T., Lutti, A., Josephs, O., Sereno, M.I., Weiskopf, N., 2012. In vivo functional and myeloarchitectonic mapping of human primary auditory areas. J. Neurosci. 32 16095-16105

Emmorey, K., Allen, J.S., Bruss, J., Schenker, N., Damasio, H., 2003. A morphometric analysis of auditory brain regions in congenitally deaf adults. Proc. Natl. Acad. Sci. U. S. A. 100, 10049-10054

Fine, I., Finney, E.M., Boynton, G.M., Dobkins, K.R., 2005. Comparing the effects of auditory deprivation and sign language within the auditory and visual cortex. J. Cogn. Neurosci. 17, 1621-1637.

Finney, E.M., Fine, I., Dobkins, K.R., 2001. Visual stimuli activate auditory cortex in the deaf. Nat. Neurosci. 4,1171-1173.

Fischl, B., Dale, A.M., 2000. Measuring the thickness of the human cerebral cortex from magnetic resonance images. Proc. Natl. Acad. Sci. U. S. A. 97, 11050-11055.

Fischl, B., Liu, A., Dale, A.M., 2001. Automated manifold surgery: constructing geometrically accurate and topologically correct models of the human cerebral cortex. IEEE Trans. Med. Imaging 20, 70-80.

Fischl, B., Salat, D.H., Busa, E., Albert, M., Dieterich, M., Haselgrove, C., van der Kouwe, A Killiany, R., Kennedy, D., Klaveness, S., Montillo, A., Makris, N., Rosen, B., Dale, A.M. 2002. Whole brain segmentation: automated labeling of neuroanatomical structures in the human brain. Neuron 33, 341-355.

Fischl, B., Van Der Kouwe, A., Destrieux, C., Halgren, E., Ségonne, F., Salat, D.H., Busa, E., Seidman, L.J., Goldstein, J., Kennedy, D., Caviness, V., Makris, N., Rosen, B., Dale, A.M. 2004. Automatically parcellating the human cerebral cortex. Cereb. Cortex 14, 11-22.

Formisano, E., Kim, D.S., Di Salle, F., van de Moortele, P.F., Ugurbil, K., Goebel, R., 2003. Mirror-symmetric tonotopic maps in human primary auditory cortex. Neuron 40, 859-869.

Geers, A.E., 2002. Factors affecting the development of speech, language, and literacy in children with early cochlear implantation. Lang. Speech Hear. Serv. Sch. 33, 172-183.

Geers, A.E., Moog, J.S., Biedenstein, J., Brenner, C., Hayes, H., 2009. Spoken language scores of children using cochlear implants compared to hearing age-mates at school entry. J. Deaf. Stud. Deaf. Educ. 14, 371-385

Giraud, A.L., Lee, H.J., 2007. Predicting cochlear implant outcome from brain organization in the deaf. Restor. Neurol. Neurosci. 25, 381-390.

Giraud, A.L., Price, C.J., Graham, J.M., Truy, E., Frackowiak, R.S.J., 2001. Cross-modal plasticity underpins language recovery after cochlear implantation. Neuron 30, 657-663.

Grosvald, M., Lachaud, C., Corina, D., 2012. Handshape monitoring: evaluation of linguistic and perceptual factors in the processing of American Sign Language. Lang. Cogn. Process. 27, 117-141.

Hackett, T.A., 2011. Information flow in the auditory cortical network. Hear. Res. 271, $133-146$

Han, X., Jovicich, J., Salat, D., van der Kouwe, A., Quinn, B., Czanner, S., Busa, E., Pacheco, J. Albert, M., Killiany, R., Maguire, P., Rosas, D., Makris, N., Dale, A., Dickerson, B., Fischl, B., 2006. Reliability of MRI-derived measurements of human cerebral cortical thickness: the effects of field strength, scanner upgrade and manufacturer. Neurolmage 32 , 180-194.

Hensch, T.K., 2004. Critical period regulation. Annu. Rev. Neurosci. 27, 549-579.

Herman, R., Roy, P., 2000. The influence of child hearing status and type of exposure to BSL on BSL acquisition. Proceedings of the 1999 Child Language Seminar, City University, London. 1, pp. 116-122.

Hubel, D.H., Wiesel, T.N., 1970. The period of susceptibility to the physiological effects of unilateral eye closure in kittens. J. Physiol. 206, 419-436.

Humphries, C., Liebenthal, E., Binder, J.R., 2010. Tonotopic organization of human auditory cortex. Neurolmage 50, 1202-1211.

Hunt, D.L., Yamoah, E.N., Krubitzer, L., 2006. Multisensory plasticity in congenitally deaf mice: how are cortical areas functionally specified? Neuroscience 139 1507-1524.

Johnson, J.A., Zatorre, R.J., 2005. Attention to simultaneous unrelated auditory and visua events: behavioral and neural correlates. Cereb. Cortex 15, 1609-1620.

Jovicich, J., Czanner, S., Greve, D., Haley, E., van der Kouwe, A., Gollub, R., Kennedy, D., Schmitt, F., Brown, G., Macfall, J., Fischl, B., Dale, A., 2006. Reliability in multi-site structural MRI studies: effects of gradient. Neurolmage 30, 436-443.

Karns, C.M., Dow, M.W., Neville, H.J., 2012. Altered cross-modal processing in the primary auditory cortex of congenitally deaf adults: a visual-somatosensory fMRI study with a double-flash illusion. J. Neurosci. 32, 9626-9638.
Kral, A., Sharma, A., 2012. Developmental neuroplasticity after cochlear implantation. Trends Neurosci. 35, 111-122.

Kral, A., Hartmann, R., Tillein, J., Heid, S., Klinke, R., 2001. Delayed maturation and sensitive periods in the auditory cortex. Audiol. Neurootol. 6, 346-362.

Kral, A., Schroder, J.H., Klinke, R., Engel, A.K., 2003. Absence of cross-modal reorganization in the primary auditory cortex of congenitally deaf cats. Exp. Brain Res. 153, 605-613.

Lambertz, N., Gizewski, E.R., de Greiff, A., Forsting, M., 2005. Cross-modal plasticity in deaf subjects dependent on the extent of hearing loss. Cogn. Brain Res. 3, 884-890.

Langers, D.R.M., 2014. Assessment of tonotopically organised subdivisions in human auditory cortex using volumetric and surface-based cortical alignments. Hum. Brain Mapp. 35, 1544-1561.

Laurienti, P.J., Burdette, J.H., Wallace, M.T., Yen, Y.F., Field, A.S., Stein, B.E., 2002. Deactivation of sensory-specific cortex by cross-modal stimuli. J. Cogn. Neurosci. 14, 420-429.

Leonard, M.K., Ferjan-Ramirez, N., Torres, C., Travis, K.E., Hatrak, M., Mayberry, R., Halgren, E., 2012. Signed words in the congenitally deaf evoke typical late lexicosemantic responses with no early visual responses in left superior temporal cortex. J. Neurosci. $32,9700-9705$

Lewkowicz, D.J., Hansen-Tift, A.M., 2012. Infants deploy selective attention to the mouth of a talking face when learning speech. Proc. Natl. Acad. Sci. U. S. A. 109, 1431-1436.

Lomber, S.G., Meredith, M.A., Kral, A., 2010. Cross-modal plasticity in specific auditory cortices underlies visual compensations in the deaf. Nat. Neurosci. 13, 1421-1427.

Lyness, C.R., Woll, B., Campbell, R., Cardin, V., 2013. How does visual language affect crossmodal plasticity and cochlear implant success? Neurosci. Biobehav. Rev. 37, 2621-2630

Lyness, C.R., Alvarez, I., Sereno, M.I., MacSweeney, M., 2014. Microstructural differences in the thalamus and thalamic radiations in the congenitally deaf. NeuroImage 100, 347-357.

MacSweeney, M., Woll, B., Campbell, R., McGuire, P.K., David, A.S., Williams, S.C., Suckling, J., Calvert, G.A., Brammer, M.J., 2002. Neural systems underlying British Sign Language and audio-visual English processing in native users. Brain 125, 1583-1593.

MacSweeney, M., Capek, C.M., Campbell, R., Woll, B., 2008. The signing brain: the neurobiology of sign language. Trends Cogn. Sci. 12, 432-440.

Mangus, B.D., Krueger-Fister, J., Stevenson, R.A., Sheffield, S.W., Hedley-Williams, A.J., Gifford, R.H., Labadie, R.F., Wallace, M.T., 2012. Plasticity in multisensory temporal processing after cochlear implantation. Society for Neuroscience Conference, p. 369.304

McGurk, H., MacDonald, J., 1976. Hearing lips and seeing voices. Nature 264, 746-748.

Merabet, L.B., Pascual-Leone, A., 2010. Neural reorganization following sensory loss: the opportunity of change. Nat. Rev. Neurosci. 11, 44-52.

Meredith, M.A., Allman, B.L., 2012. Early hearing-impairment results in crossmodal reorganization of ferret core auditory cortex. Neural Plast. 601591.

Meredith, M.A., Lomber, S.G., 2011. Somatosensory and visual crossmodal plasticity in the anterior auditory field of early-deaf cats. Hear. Res. 280, 38-47.

Meredith, M.A., Kryklywy, J., McMillan, A.J. Malhotra, S., Lum-Tai, R., Lomber, S.G. 2011. Crossmodal reorganization in the early deaf switches sensory, but not behavioral roles of auditory cortex. Proc. Natl. Acad. Sci. U. S. A. 108, 8856-8861.

Mills, A.E., 1987. The language of blind children: normal or abnormal. In: Jordens, P., Lalleman, J. (Eds.), Language Development. Foris Publication Holland, Dordrecht.

Morosan, P., Rademacher, J., Schleicher, A., Amunts, K., Schormann, T., Zilles, K., 2001. Human primary auditory cortex: cytoarchitectonic subdivisions and mapping into a spatial reference system. NeuroImage 13, 684-701.

Neville, H.J., Bavelier, D., Corina, D., Rauschecker, J., Karni, A., Lalwani, A., Braun, A., Clark, V., Jezzard, P., Turner, R., 1998. Cerebral organization for language in deaf and hearing subjects: biological constraints and effects of experience. Proc. Natl. Acad. Sci. U. S. A. 95, 922-929.

O'Donoghue, G.M., Nikolopoulos, T.P., Archbold, S.M., 2000. Determinants of speech perception in children after cochlear implantation. Lancet 356, 466-468.

Olulade, O.A., Koo, D.S., LaSasso, C.J., Eden, G.F., 2014. Neuroanatomical profiles of deafness in the context of native language experience. J. Neurosci. 34, 5613-5620.

Orfanidou, E., Adam, R., McQueen, J.M., Morgan, G., 2009. Making sense of nonsense in British sign language (BSL): the contribution of different phonological parameters to sign recognition. Mem. Cogn. 37, 302-315.

Pekkola, J., Ojanen, V., Autti, T., Jääskeläinen, I.P., Möttönen, R., Tarkiainen, A., Sams, M., 2005. Primary auditory cortex activation by visual speech: an fMRI study at $3 \mathrm{~T}$. Neuroreport 16, 125-128.

Penhune, V.B., Cismaru, R., Dorsaint-Pierre, R., Petitto, L.A., Zatorre, R.J., 2003. The morphometry of auditory cortex in the congenitally deaf measured using MRI. Neurolmage 20, 1215-1225.

Reich, L., Szwed, M., Cohen, L., Amedi, A., 2011. A ventral visual stream reading center independent of visual experience. Curr. Biol. 21, 363-368.

Rönnberg, J., Soderfeldt, B., Risberg, J., 1998. Regional cerebral blood flow during signed and heard episodic and semantic memory tasks. Appl. Neuropsychol. 5 , 132-138.

Rouger, J., Lagleyre, S., Fraysse, B., Deneve, S., Deguine, O., Barone, P., 2007. Evidence that cochlear-implanted deaf patients are better multisensory integrators. Proc. Natl. Acad. Sci. U. S. A. 104, 7295-7300.

Sadato, N., Pascual-Leone, A., Grafman, J., Deiber, M.P., Ibanez, V., Hallett, M., 1998. Neural networks for braille reading by the blind. Brain 121, 1213-1229.

Sadato, N., Okada, T., Honda, M., Matsuki, K., Yoshida, M., Kashijura, K., Takei, W., Sato, T., Kochiyama, T., Yonekura, Y., 2005. Cross-modal integration and plastic changes revealed by lip movements, random-dot motion and sign languages in the hearing and deaf. Cereb. Cortex 15, 1113-1122.

Sakai, K.L., Tatsuno, Y., Suzuki, K., Kimura, H., Ichida, Y., 2005. Sign and speech: amodal commonality in left hemisphere dominance for comprehension of sentences. Brain 128, 1407-1417.

Schönwiesner, M., Dechent, P., Voit, D., Petkov, C.I., Krumbholz, K., 2014. Parcellation of human and monkey core auditory cortex with fMRI pattern classification and 
objective detection of tonotopic gradient reversals. Cereb. Cortex pii: bhu124. [Epub ahead of print] PMID: 24904067.

Scott, S.K., Johnsrude, I.S., 2003. The neuroanatomical and functional organization of speech perception. Trends Neurosci. 26, 100-107.

Scott, G.D., Karns, C.M., Dow, M.W., Stevens, C., Neville, H.J., 2014. Enhanced peripheral visual processing in congenitally deaf humans is supported by multiple brain regions, including primary auditory cortex. Front. Hum. Neurosci. 8, 177 .

Ségonne, F., Dale, A.M., Busa, E., Glessner, M., Salat, D., Hahn, H.K., Fischl, B., 2004. A hybrid approach to the skull stripping problem in MRI. Neurolmage 22, 1060-1075.

Sharma, A., Campbell, J., 2011. A sensitive period for cochlear implantation in deaf children. J. Matern. Fetal Neonatal Med. 1, 151-153.

Shore, S.E., Koehler, S., Odakowski, M., Hughes, L.F., Syed, S., 2008. Dorsal cochlear nucleus responses to somatosensory stimulation are enhanced after noise-induced hearing loss. Eur. J. Neurosci. 27, 155-168.

Söderfeldt, B., Ingvar, M., Ronnberg, J., Eriksson, L., Serrander, M., Stone-Elander, S., 1997. Signed and spoken language perception studied by positron emission tomography. Neurology 49, 82-87.

Stevenson, R.A., Mangus, B.D., Krueger-Fister, J., Sheffield, S.W., Hedley-Williams, A.J., Dwyer, R.T., Gifford, R.H., Labadie, R.F., Wallace, M.T., 2012. Visual temporal processing is associated with cochlear implant auditory proficiency. Society for Neuroscience Conference, p. 316.302.

Striem-Amit, E., Hertz, U., Amedi, A., 2011. Extensive cochleotopic mapping of human auditory cortical fields obtained with phase-encoding fMRI. PLoS One 6, e17832.

Striem-Amit, E., Cohen, L., Dehaene, S., Amedi, A., 2012. Reading with sounds: sensory substitution selectively activates the visual word form area in the blind. Neuron 76, 640-652.
Tahmasebi, A.M., Abolmaesumi, P., Geng, X., Morosan, P., Amunts, K., Christensen, G.E. Johnsrude, I.S., 2009. A new approach for creating customizable cytoarchitectonic probabilistic maps without a template. Med. Image Comput. Comput. Assist. Interv. $12,795-802$.

Talavage, T.M., Sereno, M.I., Melcher, J.R., Ledden, P.J., Rosen, B.R., Dale, A.M., 2004 Tonotopic organization in human auditory cortex revealed by progressions of frequency sensitivity. J. Neurophysiol. 91, 1282-1296.

Teoh, S.W., Pisoni, D.B., Miyamoto, R.T., 2004. Cochlear implantation in adults with prelingual deafness. Part II. Underlying constraints that affect audiological outcomes. Laryngoscope 114, 1714-1719.

van den Bogaerde, B., Baker, A., 2005. Code mixing in mother-child interaction in deaf families. Sign Lang. Linguist. 8, 153-176.

Wang, N., Liu, C., Liu, S., Huang, K., Kuo, Y., 2011. Predictor of auditory performance in Mandarin Chinese children with cochlear implants. Otol. Neurotol. 32, 937-942.

Wild, C.J., Davis, M.H., Johnsrude, I.S., 2012. Human auditory cortex is sensitive to the perceived clarity of speech. Neurolmage 60, 1490-1502.

Wong, C., Chabot, N., Kok, M.A., Lomber, S.G., 2014. Modified areal cartography in auditory cortex following early- and late-onset deafness. Cereb. Cortex 24, 1778-1792.

Wong, C., Chabot, N., Kok, M.A., Lomber, S.G., 2015. Amplified somatosensory and visual cortical projections to a core auditory area, the anterior auditory field, following early- and late-onset deafness. J. Comp. Neurol. http://dx.doi.org/10.1002/cne.23771

Woods, D.L. Stecker, G.C. Rinne, T. Herron, TJ Cate, A.D, Yund, E.W Liao, I., Kang X. 2009. Functional maps of human auditory cortex: effects of acoustic features and attention. PLoS One 4, e5183.

Zeng, C., Yang, Z., Shreve, L., Bledsoe, S., Shore, S., 2012. Somatosensory projections to cochlear nucleus are upregulated after unilateral deafness. J. Neurosci. 32, 15791-15801. 